\title{
APLIKASI ROTASI TATA SURYA BERBASIS AUGMENTED REALITY
}

\author{
Adelia Alfama Zamista ${ }^{1}$, Nur Budi Nugraha ${ }^{2}$ \\ 1)Program Studi Teknik Industri, Sekolah Tinggi Teknologi Dumai \\ 2)Program Studi Informatika, Sekolah Tinggi Teknologi Dumai \\ Jl. Utama Karya Bukit Batrem II \\ Email: alfadelia17@gmail.com
}

\begin{abstract}
ABSTRAK
Augmented Reality adalah teknologi yang menggabungkan objek maya kedalam sebuah lingkungan nyata tiga dimensi dan menampilkannya dalam waktu nyata. Tidak seperti realitas maya yang sepenuhnya menggantikan kenyataan, augmented reality hanya sekedar menambahkan atau melengkapi kenyataan dengan mengijinkan penggunanya untuk berinteraksi secara real time terhadap sistem. Pada tugas akhir ini, penulis mencoba membuat salah satu metode pembelajaran dengan menggunakan bantuan augmented reality agar pembelajaran tentang sistem rotasi tata surya menjadi semakin menarik dan interaktif serta dapat menumbuhkan minat belajar masyarakat.
\end{abstract}

Kata kunci: Augmented Reality, tata surya, 3DMax.

\begin{abstract}
Augmented Reality is a technology that combines virtual objects into a real threedimensional environment and displays them in real time. Unlike virtual reality that completely replaces reality, augmented reality simply adds or complements reality by allowing users to interact in real time with the system. In this final project, the writer tries to make one of the learning method by using the augmented reality aid so that the learning about solar system rotation becomes more interesting and interactive and can foster the learning interest of the community.
\end{abstract}

Keywords: Augmented Reality, solar system, 3DMax.. 


\section{Pendahuluan}

Augmented Reality (disingkat menjadi AR) adalah menggabungkan dunia nyata dan virtual, bersifat interaktif secara real time, dan bentuknya merupakan animasi 3D. Ada tiga prinsip dari augmented reality. Yang pertama yaitu AR merupakan penggabungan dunia nyata dan virtual, yang kedua berjalan secara interaktif dalam waktu nyata (real-time), dan yang ketiga terdapat integrasi antar benda dalam tiga dimensi, yaitu benda maya terintegrasi dalam dunia nyata (Ronald T. Azuma,1997).

Tidak seperti realitas maya yang sepenuhnya menggantikan kenyataan, AR hanya sekedar menambahkan atau melengkapi kenyataan dengan mengijinkan penggunanya untuk berinteraksi secara real-time terhadap sistem. AR menjadi sangat populer saat ini karena selain menarik, AR juga dapat digunakan di berbagai aspek kehidupan seperti dalam pembelajaran. Dengan bantuan AR, pembelajaran seperti sistem tata surya dapat dibuat menjadi lebih menarik dan interaktif. AR mampu memberikan pengalaman dan pemahaman yang lebih mendalam bagi subjek pembelajaran(Iwan Setya Nugraha, Kodrat Iman Satoto, Kurniawan Teguh Martono.2009).

Pengguna dapat secara langsung mengamati objek tiga dimensi berbentuk tata surya dan melakukan pembelajaran yang lebih mudah dibandingkan dengan gambar dua dimensi. Objek tiga dimensi yang dihasilkan AR dapat memotivasi pengguna dan menimbulkan rasa ingin tahu yang lebih karena sistem pembelajaran AR yang berbeda dengan pembelajaran yang sudah ada. Pembelajaran yang memanfaatkan AR merupakan sesuatu yang baru dalam masyarakat.

\section{Metode Penelitian}

Perancangan implementasi augmented reality sebagai media pembelajaran pada materi tata surya dilakukan melalui tahap-tahap berikut: 1) tahap perencanaan, 2) tahap perancangan tampilan, 3) implementasi pada arttoolkit.

1. Tahap Perencanaan

Pada tahap ini dilakukan perancangan dari aplikasi Augmented reality baik dalam rancangan tampilan serta modul-modul yang diperlukan dalam pembuatan aplikasi Augmented reality dan mempelajari metode marker agar dapat dipergunakan. Serta implementasinya menggunakan Android.

2. Tahap perancangan tampilan

Tahap kedua merupakan tahap perancangan tampilan, dimulai dengan mengambar object sesuai dengan materi tata surya. Dan dilanjutkan dengan membuat rancangan Model 3D dengan mengunakan 3Ds max 9 .

3. Implementasi pada ArtToolkit 
Tahap akhir dilakukan percobaan apakah program yang telah dibuat dapat berjalan dengan baik pada ARToolkit.

\section{Hasil dan Pembahasan}

Bagian hasil dan pembahasan ini akan memaparkan rincian proses materi rotasi tata surya menjadi aplikasi berbasis augmented reality. Augmented reality merupakan penggabungan dari benda nyata dan maya pada lingkungan sebenarnya, dengan waktu yang pada saat itulah dan terdapat integrasi antar benda dalam bentuk 3D, yaitu benda maya terintegrasi dalam dunia nyata. Penggabungan benda nyata dan maya dalam bentuk 3D dengan menggunakan perangkat-perangkat program tertentu dan memiliki integritas yang handal memerlukan suatu pengamatan yang efektif (Kurniawan Teguh Martono, 2011).

Augmented Reality memiliki cara kerja yang cukup sederhana dengan berdasarkan deteksi citra dan biasa disebut dengan marker. Sebagai contoh, sebuah kamera telah dikalibrasi dapat mendeteksi marker yang telah didesain, lalu setelah mendeteksi marker tersebut, kamera akan melakukan pencocokan dengan database yang telah dibuat sebelumnya. Dan jika hasilnya cocok, maka informasi dari marker akan digunakan menampilkan objek 3D yang telah didesain di depan layar (Apri Santoso, Elki Noviandi, Iis Pradesan, 2013).

Tahap pertama penulis melakukan persiapan awal untuk perancangan system ini secara umum.

\section{Arsitektur Aplikasi}

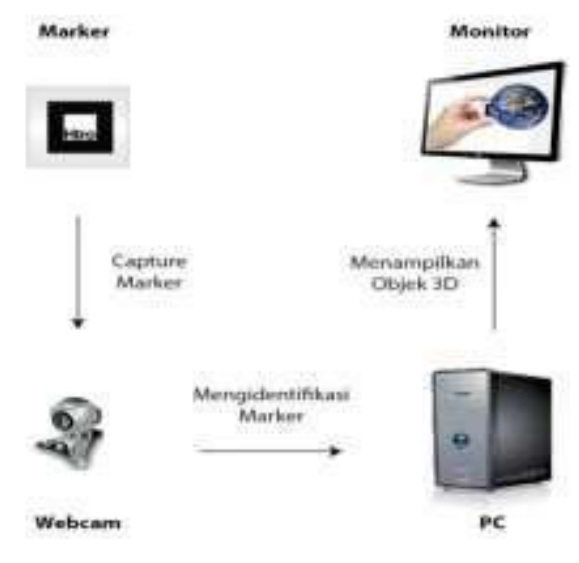

Gambar 1. Arsitektur Aplikasi 


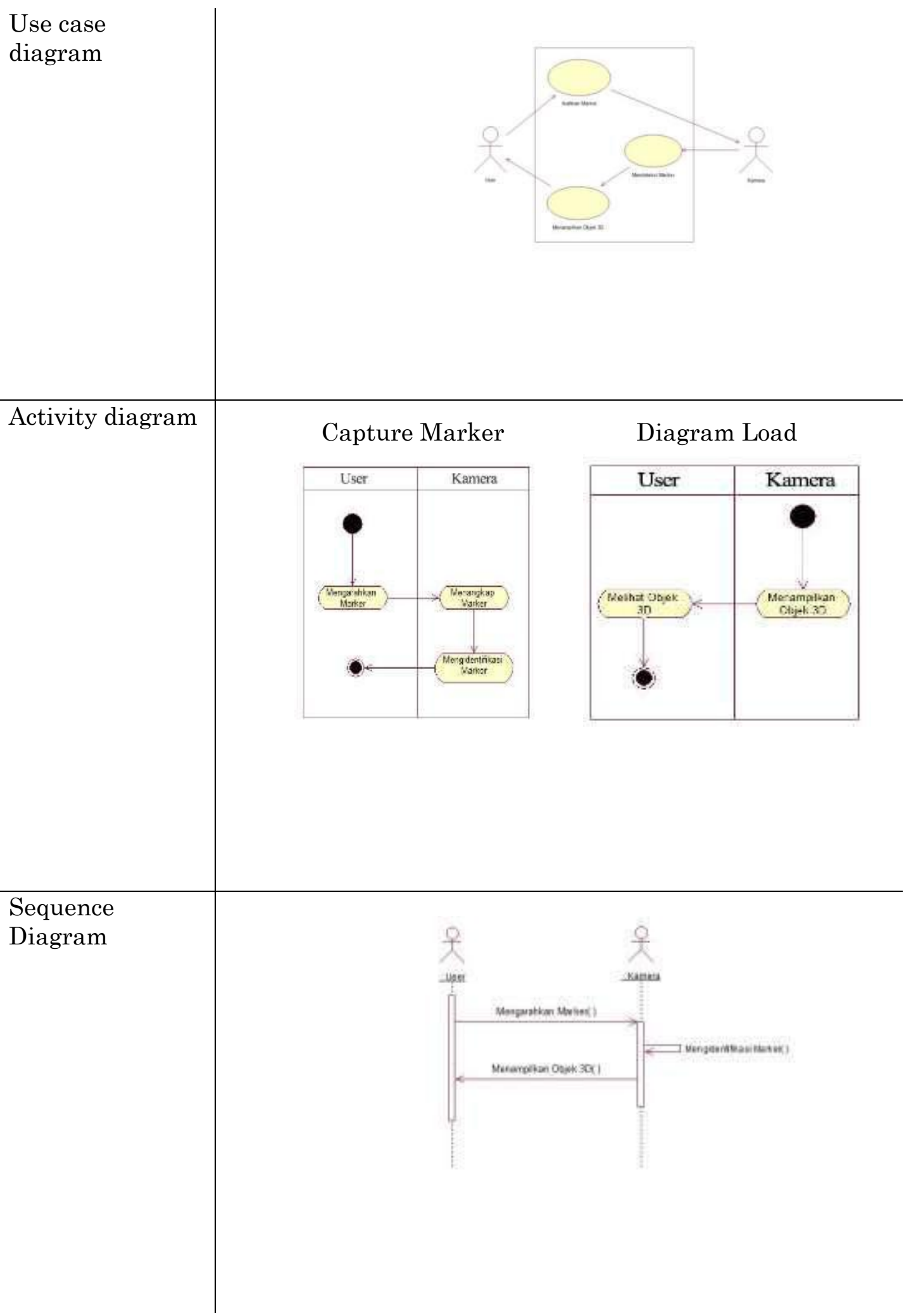

Prosedure Augmented Reality

UNITEK. Vol. 10 No. 2 Juli - Desember 2017

| p-ISSN 2089-3957 | e-ISSN 2580-2585 
Berikut ini merupakan prosedur kerja augmented reality:

1. Kamera mencari marker, kemudian marker yang dideteksi dirubah menjadi binary, kemudian black frame atau bingkai hitam terdeteksi oleh kamera.

2. Kamera menemukan posisi marker 3D dan dikalkulasikan dengan kamera nyata.

3. Kamera mengidentifikasi marker, apakah pola marker sesuai dengan templates memory.

4. Dengan mentransformasikan posisi marker.

5. Objek 3d di render di atas marker.

\section{RANCANGAN APLIKASI}

\section{Prosedur Pembuatan Marker}

Berikut ini merupakan prosedur pembuatan marker :

1. Buka file BlankPath yang ada di folder ARToolkit $\backslash$ Pattern $\backslash$ dengan photoshop.

2. Di BlankPath kita akan melihat di tengah pattern masih kosong. Di tengah pola yang masih kosong itulah kita bias mengisi gambar berwarna atau hitam-putih.

3. Setelah pola selesai kemudian langsung di print dari photoshop marker yang telah kita buat.

4. Agar marker yang kita buat dikenali oleh ARToolkit sehingga kita bias menggunakannya, maka langkah yang kita lakukan adalah :

(a) Membuka windows explorer $>$

ARToolkit $\backslash$ Bin $\backslash$ (b) Buka mk_patt.exe (c) Jika ada bacaan "camera parameter filename<data/camera_para.dat>:" tekan enter. (d) Jika tampil menu "Property Sheet Properties", langsung klik OK (e) Setelah itu akan tampil layar kamera. (f) Setelah layar kamera keluar, arahkan marker yang kita buat kea rah kamera. Bila mk_patt.exe mengeluarkan garis hijau dan merah di sekeliling bingkai langsung klik layar kamera untuk di capture (g) Selanjutnya masuk ke mk_patt.exe dan ketikkan nama marker yang kita buat dengan format patt.(nama marker) contohnya patt.tatasurya (h) Untuk melihat hasil marker kita, cukup masuk ke folder ARToolkit $\backslash$ Bin $\backslash$ kemudian cari file patt.(nama marker) (i) Selanjutnya copy-paste patt.(nama marker) ke folder ARToolkit $\backslash$ Bin $\backslash$ Data $\backslash$ (j) Untuk dapat menggunakan marker tersebut selanjutnya kita dapat menambahkan marker tersebut di file object_data_vrml dan jalankan simplevrml.exe 


\section{Rancangan Form Utama}

Rancangan form utama ini digunakan sebagai halaman utama pada aplikasi kami. Di halaman utama ini, pengguna dapat memilih menu beranda, simulasi rotasi, spesifikasi planet, tentang kami dan keluar. Berikut rancangan halaman utama tersebut.

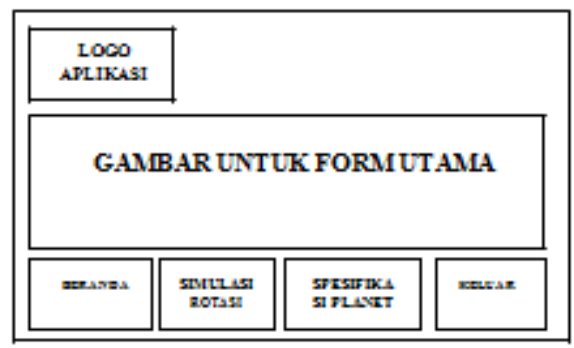

\section{Rancangan Form Beranda}

Rancangan form beranda ini digunakan untuk memberikan informasi tentang aplikasi yang kami buat.

\section{Rancangan Form Simulasi Rotasi}

Rancangan form simulasi rotasi digunakan untuk menampilkan aplikasi simulasi rotasi tata surya yang telah kami buat dengan menggunakan marker untuk simulasi rotasi yang telah di desain khusus. Berikut rancangan halaman simulasi rotasi tata surya.

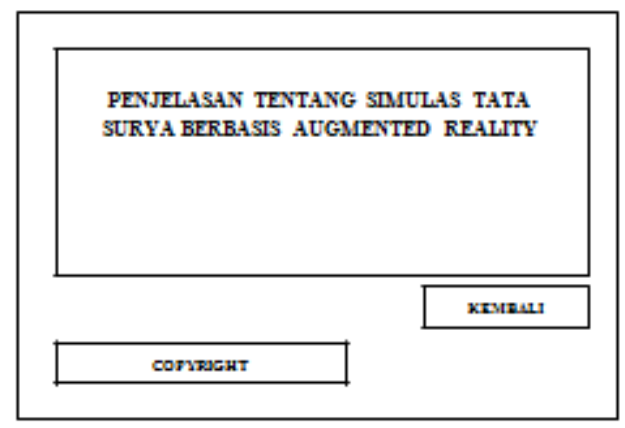

\section{Rancangan Form Spesifikasi Planet}

Rancangan form spesifikasi planet digunakan untuk menampilkan aplikasi spesifikasi planet-planet yang telah kami buat dengan menggunakan marker-marker yang telah di desain khusus. Berikut rancangan halaman simulasi rotasi tata surya.

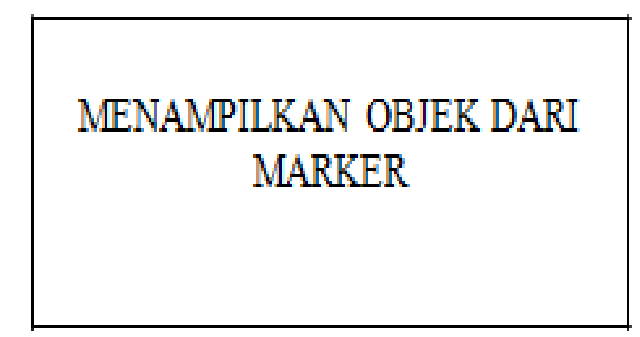




\section{PENGUJIAN SISTEM}

Pada pengujian ini,penulis melakukan pengujian untuk menampilkan objek planet-planet beserta spesifikasinya sesuai dengan marker yang digunakan.

\section{Pengujian Pada Penanda Atau Marker}

Tabel 1. Pengujian penanda atau marker

\begin{tabular}{|c|l|c|}
\hline $\begin{array}{c}\text { Test } \\
\text { Factor }\end{array}$ & Hasil & Keterangan \\
\hline $\begin{array}{c}\text { 1. Marker } \\
\text { Hitam } \\
\text { Putih }\end{array}$ & $\checkmark$ & $\begin{array}{c}\text { Objek tamp il } \\
\text { sesuai dengan } \\
\text { markernya. }\end{array}$ \\
\hline $\begin{array}{c}\text { 2. Marker } \\
\text { Berwarna }\end{array}$ & $\checkmark$ & $\begin{array}{c}\text { Objek tamp i1 } \\
\text { sesuai dengan } \\
\text { markernya. }\end{array}$ \\
\hline
\end{tabular}

Pada tabel diatas dapat kita lihat bahwa marker yang diuji baik yang berwarna ataupun yang hanya hitam putih keduanya dapat menampilkan objek sesuai dengan markernya.

\section{Pengujian Sudut Dan Jarak Kamera Dengan Penanda Atau Marker}

Pada pengujian ini, penulis melakukan pengujian terhadap sudut kemiringan $45^{\circ}$ dan jarak letak kamera terhadap penanda atau marker untuk mendapatkan pendeteksian penanda atau marker yang baik. Posisi kamera pada ketinggian tetap yaitu $23 \mathrm{~cm}$.

Tabel 2. Pengujian sudat dan jarak kamera

\begin{tabular}{|c|c|c|}
\hline Test Factor & Hasil & Keterangan \\
\hline $\begin{array}{c}\text { 1. Jarak } \\
\text { Terpendek }= \\
+11(\mathrm{~cm})\end{array}$ & $\boldsymbol{V}$ & $\begin{array}{c}\text { Objek } \\
\text { berhasil } \\
\text { tampil. }\end{array}$ \\
\hline $\begin{array}{c}\text { 2. Jarak } \\
\text { Terjauh }= \\
+86(\mathrm{~cm})\end{array}$ & $\boldsymbol{V}$ & $\begin{array}{c}\text { Objek } \\
\text { berhasil } \\
\text { tampil. }\end{array}$ \\
\hline
\end{tabular}

\section{Metode Pengujian}

Metode pengujian yang akan dilakukan terhadap sistem yang telah dirancang adalah metode pengujian statistik, yaitu dengan membuat pertanyaan atau kuesioner untuk mendapat tanggapan dari responden sesuai populasi dan sampel yang telah ditetapkan mengenai sistem baru yang telah dirancang. 
Berdasarkan data yang telah diperoleh melalui teknik pengumpulan data, maka hasil penelitian dengan metode deskripsi variabel adalah sebagai berikut :

1. Apakah aplikasi simulasi rotasi tata surya berbasis augmented reality ini dapat dijadikan sebagai salah satu metode pembelajaran tentang sistem tata surya?

Tabel 3 Tanggapan Responden I

\begin{tabular}{|l|c|c|}
\hline Tanggapan & $\begin{array}{l}\text { Responden } \\
\text { (Orang) }\end{array}$ & $\begin{array}{l}\text { Presentase } \\
\mathbf{( \% )}\end{array}$ \\
\hline 1. Ya & 9 & 90 \\
2. Tidak & 1 & 10 \\
\hline \multicolumn{1}{|c|}{ Total } & 10 & 100 \\
\hline
\end{tabular}

Pada tabel 3 di atas dapat dilihat hasil penelitian menunjukkan dari 10 responden terdapat 9 responden atau 90\% yang menyatakan dapat dijadikan sebagai salah satu metode pembelajaran tentang sistem tata surya dan 1 responden atau 10\% yang menyatakan tidak.

Dari uraian tersebut dapat diketahui bahwa aplikasi simulasi rotasi tata surya berbasis augmented reality ini dapat dijadikan sebagai salah satu metode pembelajaran tentang sistem tata surya.

2. Apakah dengan adanya aplikasi seperti ini dapat membuat pembelajaran tentang sistem tata surya menjadi lebih menarik?

Tabel 4. Tanggapan responden II

\begin{tabular}{|l|c|c|}
\hline Tanggapan & $\begin{array}{l}\text { Respond } \\
\text { en } \\
\text { (Orang) }\end{array}$ & $\begin{array}{l}\text { Presenta } \\
\text { se } \\
\text { (\%) }\end{array}$ \\
\hline \begin{tabular}{l|c|} 
1. Ya \\
2. Belum
\end{tabular} & 9 & 90 \\
\hline Total & 10 & 100 \\
\hline
\end{tabular}


Pada tabel 4 di atas dapat dilihat hasil penelitian menunjukkan dari 10 responden terdapat 9 responden atau 90\% yang menyatakan dapat membuat pembelajaran tentang sistem tata surya menjadi lebih menarik dan 1 responden atau 10\% yang menyatakan belum.

Dari uraian tersebut dapat diketahui bahwa aplikasi simulasi rotasi tata surya berbasis augmented reality ini dapat membuat pembelajaran tentang sistem tata surya menjadi lebih menarik.

\section{Simpulan}

Pembuatan aplikasi pembelajaran 3 dimensi rotasi tata surya berbasis augmented reality ini dimulai dari analisis kebutuhan sampai dengan pengujian aplikasi. Aplikasi pembelajaran 3d berbasis Augmented Reality dapat dibangun dengan menggunakan aplikasi ARtoolkit dan menggunakan metode MSF( Microsoft Solutions Framework). Sebagai suatu media pembelajaran yang menampilkan rotasi tata surya secara 3 dimensi Augmented Reality menjadi alternatif media pembelajaran yang menarik. 


\section{Daftar Pustaka}

Azuma, Ronald T. (1997). A Survey of Augmented Reality, diakses 20 November 2014, dari http://www.cs.unc.edu/ azuma/AR pres ence.pdf

Iwan Setya Nugraha,Kodrat Iman Satoto, Kurniawan Teguh Martono, Pemanfaatan Augmented Reality Untuk Pembelajaran Pengenalan Alat Musik Piano,2009.

TeguhMartono,Kurniawan, Augmented Reality Sebagai Metafora Baru dalam Teknologi Interaksi Manusia dan Komputer, Jurnal Sistem Komputer - Vol.1, No.2, Oktober 2011.

Ariyanto Bowo Dwi, Hariadi Mochammad, Mardi Supeno. 2011, Simulasi Perilaku Pergerakan Objek 3D Media Augmented Reality Berbasis Logika FUZZY, Diakses tanggal 20 November 2014 dari http://digilib.its.ac.id/public/ITS-Master-18002-2208205730-Paper1.pdf

Gorbala, Bregga Tedy dan Mochamad Hariadi. 2010. Aplikasi Augmented Reality untuk Katalog Penjualan Rumah.

RistyAmmatia . 2012 , Augmented Reality Paper, Diakses tanggal 5 Desember 2014.

Santoso Apri, Elki Noviandi, Iis Pradesan. 2013, Rancang Bangun Aplikasi Pembelajaran Organ Tubuh Berbasis Augmented Reality.

Z Muttaqin. 2014. Rancang Bangun Aplikasi 3d Pada Pengenalan Tata Surya Berbasis Augmented Reality 